\title{
Functional Organization in the Ferret Visual Cortex: A Double-Label 2-Deoxyglucose Study
}

\author{
C. Redies, ${ }^{1}$ M. Diksic, ${ }^{1}$ and H. Riml ${ }^{2}$ \\ 'Montreal Neurological Institute and Department of Neurology and Neurosurgery, McGill University, Montreal, Quebec, \\ Canada H3A 2B4, and 'Medical Physics Unit, McGill University, Montreal, Quebec, Canada H2W 1S4
}

The functional organization of visual cortical area $17 / 18$ of the ferret was studied using a double-label 2-deoxyglucose (2-DG) method. Animals were stimulated sequentially with moving gratings of 2 different orientations. Elongated orientational patches running roughly at a right angle into the area $17 / 18$ border were seen. The orientation maps were similar in areas 17 and 18 . When animals were stimulated with 2 orthogonally oriented gratings, activation patterns were not fully complementary but did not overlap. A complex pattern of partial overlap was observed, with orientations differing by $45^{\circ}$. More gradual and more abrupt changes alternated frequently on a scale smaller than the average periodicity in the patterns. A cortical patch representing a given orientation was regularly surrounded by both neighboring and orthogonal orientations. The direction of the orientational changes reversed frequently in the immediate vicinity of any orientational patch.

Orientation maps were compared with complete maps of retino-cortical projections obtained by transneuronal labeling with intravitreally injected tritiated proline. Ocular dominance in the binocular segment of both areas 17 and 18 was found to be organized into elongated ipsilateral islands in an almost contiguous contralateral projection. In area 18, the patches were wider than in area 17, and the ipsilateral islands were smaller in the regions representing the upper and central visual field than in those representing the lower visual field.

In many mammalian species, the visual cortex is organized into functional subunits or gradients that extend perpendicular to the cortical surface (columns). Examples of such an organization are the orientation and ocular dominance columns in the cat, tree shrew, and monkey visual cortices (Wiesel et al., 1974; Kennedy et al., 1976; Hubel et al., 1977; Humphrey et al., 1980; Singer, 1981; Albus and Sieber, 1984; LeVay et al., 1985; Blasdel and Salama, 1986; Löwel et al., 1987; Tootell et al., 1988).

\footnotetext{
Received Dec. 19, 1989; revised Mar. 27, 1990; accepted Apr. 16, 1990.

This work was supported by the Medical Research Council of Canada through Grant MA-10233 to M. Diksic, Y. L. Yamamoto, and C. Redies, and a postdoctoral fellowship to C. Redies. We wish to thank Dr. Lucas Y. Yamamoto for his interest in this study, Ms. Jeanette Green and the animal facilities staff for their dedicated animal care, Ms. Susan Kaupp for helping to prepare the figures, and Ms. Rachel Carnell for making stylistic improvements in the manuscript. This work was presented, in preliminary form, at the Society for Neuroscience Meeting in Phoenix, Arizona, 1989.

Correspondence should be addressed to Dr. Christoph Redies, Department of Biophysics, Faculty of Science, Kyoto Iniversity, Kitashirakawa, Sakyo-ku, Kyoto 606 , Japan.
}

Copyright (C) 1990 Society for Neuroscience $0270-6474 / 90 / 082791-13 \$ 03.00 / 0$
Within a column, neurons have similar response properties, such as orientational or eye-specific excitability. Across the cortical surface, functional columns map in an irregularly repetitive manner.

In this study, the spatial relationship of different orientation columns was investigated in visual cortical area $17 / 18$ of the ferret (Mustela putorius furo) by metabolic labeling with 2-deoxy-D-glucose (2-DG). To separately map 2 different functional activation patterns in the same ferret, a modification of the quantitative double-label 2-DG method (Redies el al., 1987; Redies and Diksic, 1989b) was used. Unlike previously proposed double-label 2-DG methods (Livingstone and Hubel, 1981; Olds et al., 1985; John et al., 1986; Friedman et al., 1987, 1989), the method used in this study corrects for the metabolic uptake and loss of the first injected tracer occurring during the second stimulation. The ferret is well suited for 2-DG studies because of its small body weight (Redies et al., 1989). Compared to cats and macaques, experiments in ferrets require relatively small amounts of $2-\mathrm{DG}$, thereby greatly reducing cxpcrimental costs. In studies of the visual system and its development, the ferret has gained interest as an alternative to the cat (Linden et al., 1981; Stryker and Zahs, 1983; Cucchiaro and Guillery, 1984; Jackson et al., 1989; Rockland, 1985; Law et al., 1988).

The orientation maps obtained with $2-\mathrm{DG}$ were compared to maps of the retino-cortical projections obtained by transneuronal labeling with intravitreally injected ${ }^{3} \mathrm{H}$-proline (Specht and Grafstein, 1973; Wiesel et al., 1974). Mustelides like the ferret have both a central binocular visual field and a large monocular segment in the peripheral visual field. Their ocular dominance pattern is therefore of particular interest (McConnell and LeVay, 1986; LeVay et al., 1987; Law et al., 1988).

\section{Materials and Methods}

Animal preparation. Young adult female ferrets (Marshall Farms, North Rose, NY) of the darkly pigmented Sable-Fitch strain were housed in accordance with institutional guidelines. The ferrets weighed about 900 $\mathrm{gm}$. Animals were fasted overnight before the experiment. Under $2 \%$ $3 \%$ halothane anesthesia, 6 animals were prepared for quantitative 2-DG procedures by unilaterally catheterizing the femoral vein and artery with PE50 tubing for tracer injection and blood sampling. Animals were tracheotomized, the trachea was lubricated with lidocaine gel (Xylocain, $2 \%$; Astra, Canada), and a tracheal tube was inserted for artificial respiration. Tracheal and femoral catheters were immobilized and wounds closed after topical lidocaine gel was applied to all wound margins.

After the surgical procedures were completed, the ferrets were placed in their natural position with the head and lower trunk elevated. Animals were switched from halothane to $\mathrm{N}_{2} \mathrm{O}: \mathrm{O}_{2}(70 \%: 30 \%)$ and paralyzed with an intravenous injection of tubocurare $(0.1 \mathrm{mg} / \mathrm{kg})$ and gallamine triethiodide $(1 \mathrm{mg} / \mathrm{kg})$. Tubocurare $(0.5 \mathrm{mg} / \mathrm{kg} / \mathrm{hr})$ and gallamine triethiodide $(7 \mathrm{mg} / \mathrm{kg} / \mathrm{hr})$ were then continuously infused intravenously in sterile saline $(2 \mathrm{ml} / \mathrm{kg} / \mathrm{hr})$. Arterial blood pressure was monitored continuously 




Figure 1. Average plasma radioactivity of 6 double-label 2-DG experiments. Radioactivities are normalized to $1 \mathrm{mCi}$ of injected isotope. The two left curves represent the $\left[{ }^{3} \mathrm{H}\right]$ radioactivity before (dashed line) and after (solid line) subtraction of the evaporable plasma radioactivity (see Materials and Methods). Error bars: SD, 1.

after surgery and during the experiment to detect any stress caused to the animal. Blood pressure readings below $150 \mathrm{~mm} \mathrm{Hg}$ and the absence of blood pressure fluctuations confirmed that the animals were not stressed. Occasional application of an innocuous stimulus to the foot before and during the experiment reliably caused a temporary increase in blood pressure readings.

Animals were artificially ventilated by a Harvard Respirator (stroke volume, 15-20 ml). Arterial blood gases were measured at least every $45 \mathrm{~min}$ and kept within physiological limits $\left(\mathrm{pO}_{2}, 70-100 \mathrm{~mm} \mathrm{Hg} ; \mathrm{pCO}_{2}\right.$, $36-43 \mathrm{~mm} \mathrm{Hg} ; \mathrm{pH}, 7.30-7.41$ ) by adjusting the stroke rate ( $5-15$ strokes/ $\mathrm{min})$. Core body temperature was monitored with a rectal temperature probe and kept within physiological limits $\left(38.0-39.5^{\circ} \mathrm{C}\right.$; Moody et al., 1985 ) by warming the animals with a hcating blanket. Hematocrit was measured and, if values above $50 \%$ were obtained, animals were rehydrated with intravenous sterile saline infused at least $30 \mathrm{~min}$ before starting the experiment.

Tracers. L- $\left[2,3-{ }^{3} \mathrm{H}\right]-$ proline (specific activity, $30 \mathrm{Ci} / \mathrm{mmol}$; Amersham) was evaporated and the compound redissolved in sterile saline. 2-[1,2-3 $\mathrm{H}]$-deoxy-D-glucose $\left(\left[1,2-{ }^{3} \mathrm{H}\right] 2-\mathrm{DG}\right)$ (specific activity, $40 \mathrm{Ci} /$ $\mathrm{mmol})$ and $2-\left[1-{ }^{14} \mathrm{C}\right]$-deoxy-D-glucose $\left(\left[1-{ }^{14} \mathrm{C}\right] 2-\mathrm{DG}\right)$ (specific activity, $55 \mathrm{mCi} / \mathrm{mmol}$ ) were purchased in sterile saline (American Radiolabeled Chemicals, St. Louis, MO), with a radiochemical and chemical purity greater than $99 \%$.

After completion of this study, it was learned that $\left[1,2-{ }^{3} \mathrm{H}\right] 2-\mathrm{DG}$ is not stable in plasma but slowly converts to an evaporable radioactive compound, probably water (Nakanishi et al., 1988). To determine how much of the plasma tracer had degraded after the injection, $30 \mu \mathrm{Ci}[1,2-$ $\left.{ }^{3} \mathrm{H}\right] 2-\mathrm{DG}$ from the batch used for the stimulation experiments was intravenously injected with $20 \mu \mathrm{Ci}$ of the stable tracer [1-14 $\mathrm{C}] 2-\mathrm{DG}$ into 2 ferrets prepared as described above. Plasma samples were obtained over a period of $90 \mathrm{~min}$ after injection. Two $20-\mu \mathrm{l}$ aliquots were processed for liquid scintillation counting. One of the samples was evaporated to dryness and redissolved in $0.5 \mathrm{ml}$ water. In agreement with results obtained by Nakanishi et al. (1988), drying of the samples resulted in a constant ${ }^{14} \mathrm{C}:{ }^{3} \mathrm{H}$ ratio during the entire experiment. For samples processed wet, the initial ${ }^{14} \mathrm{C}:{ }^{3} \mathrm{H}$ ratio was the same as that measured for the dried samples immediately after injection, but decreased to 0.96 at $30 \mathrm{~min}$, to 0.88 at $60 \mathrm{~min}$, and to 0.77 at $90 \mathrm{~min}$. These ratios were used to obtain the $\left[{ }^{3} \mathrm{H}\right] 2-\mathrm{DG}$ plasma radioactivity curves. Figure 1 shows normalized plasma curves with and without correction

Visual stimulation. Six animals were placed in a stereotaxic head holder directly in front of a semitransparent screen at a distance of 45 $\mathrm{cm}$. After aligning the head with ear bars briefly placed into the animals' ear canals, which were locally anesthetized, the head was stabilized by cushioning it with gauze pads, and the ear bars were immediately removed. Pupils were dilated and accommodation relaxed by instilling $1 \%$ atropine solution into the corneal sacs. Nictitating membranes were retracted by a topical application of $2.5 \%$ phenylephrine solution. Cus- tom-made neutral contact lenses fitting the curvature of the cornea were applied (3.0-mm base curve, 5.0-mm base diameter; Contact Lens Laboratory, Fort Mitchell, KY). Retinoscopy confirmed that the ferret, like other mustelides (Le Vay et al., 1987), has a large focal depth. No attempt was made to correct for refractive errors or to focus the retina onto the screen in front of the animals. Similar procedures have been successfully used for single-cell recordings from the mink visual system (Le Vay et al., 1987).

After the animals' vision had accommodated to the background illumination $\left(0.35 \mathrm{~cd} / \mathrm{m}^{2}\right)$ for at least $30 \mathrm{~min}$, the animals were stimulated with a pseudorandom sequence of light $\left(1.4 \mathrm{~cd} / \mathrm{m}^{2}\right)$ and dark bars $(0.4$ $\mathrm{cd} / \mathrm{m}^{2}$ ) of $0.5-8^{\circ}$ width (Fig. 2) projected onto the back of the semitransparent screen $\left(80^{\circ} \times 80^{\circ}\right)$. Bars moved orthogonally to their orientation at an average speed of $3 \% \mathrm{sec}$. The direction of movement was reversed every 3-5 min. The orientation of the bars was changed between the first and the second stimulation. The orientations used for stimulation are given in Table 1.

Experimental schedule. To assure constant anesthetic conditions, experiments were started $2-3 \mathrm{hr}$ after the switch from halothane to nitrous oxide anesthesia. The first stimulation was initiated $5 \mathrm{~min}$ before the injection of the first tracer. The experiment was started (at 0 min) with the intravenous injection of the first tracer $\left(4-5 \mathrm{mCi}\left[{ }^{3} \mathrm{H}\right] 2-\mathrm{DG}\right)$ lasting $1 \mathrm{~min}$ (Table 2). The animals continued to be stimulated for $55 \mathrm{~min}$ after the start of the first injection. At $55 \mathrm{~min}$, the second stimulation was started. At $60 \mathrm{~min}, 20-25 \mu \mathrm{Ci}\left[{ }^{14} \mathrm{C}\right] 2-\mathrm{DG}$ was injected over $1 \mathrm{~min}$ as the sccond tracer (Table 2). The second stimulation continued until $88 \mathrm{~min}$. The animals were deeply anesthetized at $89 \mathrm{~min}$ with intravenous pentobarbitol $(100 \mathrm{mg} / \mathrm{kg})$. At $90 \mathrm{~min}$, the animals were decapitated to stop any remaining cerebral circulation. The $60 / 30 \mathrm{~min}$ schedule for tracer circulation was used because it causes less uptake of the first tracer during the second stimulation than other schedules (Redies et al., 1987; Redies and Diksic, 1989a, b).

Determination of plasma radioactivity, plasma glucose, and arterial hematocrit. To determine plasma radioactivity, timed arterial blood samples $(60 \mu \mathrm{l})$ were obtained at $0.5,1,2,3,5,7,10,15,25,35,45$, $60.5,61,62,63,65,67,70,75,80$, and $89.5 \mathrm{~min}$. Blood samples were immediately placed on ice to minimize any further metabolism of 2-DG by red blood cells. Plasma radioactivities were determined in a liquid scintillation counter (1219 Rackbeta, LKB, Bromma, Sweden) after the blood samples were spun down in a centrifuge. Twenty- $\mu \mathrm{l}$ plasma aliquots were dissolved in $10 \mathrm{ml}$ of scintillation fluid (ScintiVerse I, Fisher, Fair Lawn, NY).

Plasma glucose levels were enzymatically measured as described previously (Redies et al., 1989). Mean plasma glucose was $149 \pm 15 \mathrm{mg} /$ $\mathrm{dl}($ mean $\pm \mathrm{SD})$. Arterial hematocrit was measured at hourly intervals after completion of surgery to assure that adequate hydration was maintained. Hematocrit was also determined at the beginning and at the end of each experiment (mean value, $47 \% \pm 4 \%$ ).

Processing of brain tissue. Immediately after decapitation, the brains were quickly removed from the skull. The 2 occipital lobes forming a fold onto the cerebellum (Rockland, 1985) were separated from the rest of the brain. Each occipital lobe was cut in a mediolateral plane along the white matter projection. The upper and lower cortical sheets of each occipital fold were placed on a metal plate to flatten the cortex. Attempts to flatten the splenial sulcus as well were not successful. The brain tissues were immersed in liquid freon on the metal plates $\left(-30^{\circ} \mathrm{C}\right.$; Histofreeze, Fisher Scientific). The frozen cortical tissues were removed from the plates and mounted on kryostat blocks. Care was taken to avoid thawing of the visual cortical gray matter during mounting. Tissues were cut tangential to the cortical surface in a microtome refrigerated to $-19^{\circ} \mathrm{C}$. Serial $20-\mu \mathrm{m}$-thick sections were mounted on microscope slides and thawed and dried on a plate heated to $65^{\circ} \mathrm{C}$. As a control, a few coronal sections from the frontal lobe were prepared in the same way.

Autoradiographic procedures. Dried sections were exposed to Ultrofilm (LKB, Bromma, Sweden) for 1 week and to SB-5 film (Kodak, Rochester, NY) for 6-8 weeks. To minimize blackening of the SB- 5 film by tritium radiation, a 5- $\mu$ m-thick polyester sheet (Mylar, 1928 Sample, Item 35726, DuPont, Canada) was interposed between the brain sections and the film. The additional distance between the film and the source of radiation was small compared to the range of the ${ }^{14} \mathrm{C}$ radiation. Compared to a similar approach using a 50- $\mu \mathrm{m}$ mylar sheet (Friedman et al., 1987), spatial resolution was less decreased in the present study. Plastic ${ }^{14} \mathrm{C}$ tissue radioactivity standards (American Radiolabeled, St. Louis, MO) were co-exposed with the sections. These standards were calibrated against brain paste standards made in our laboratory. Various 


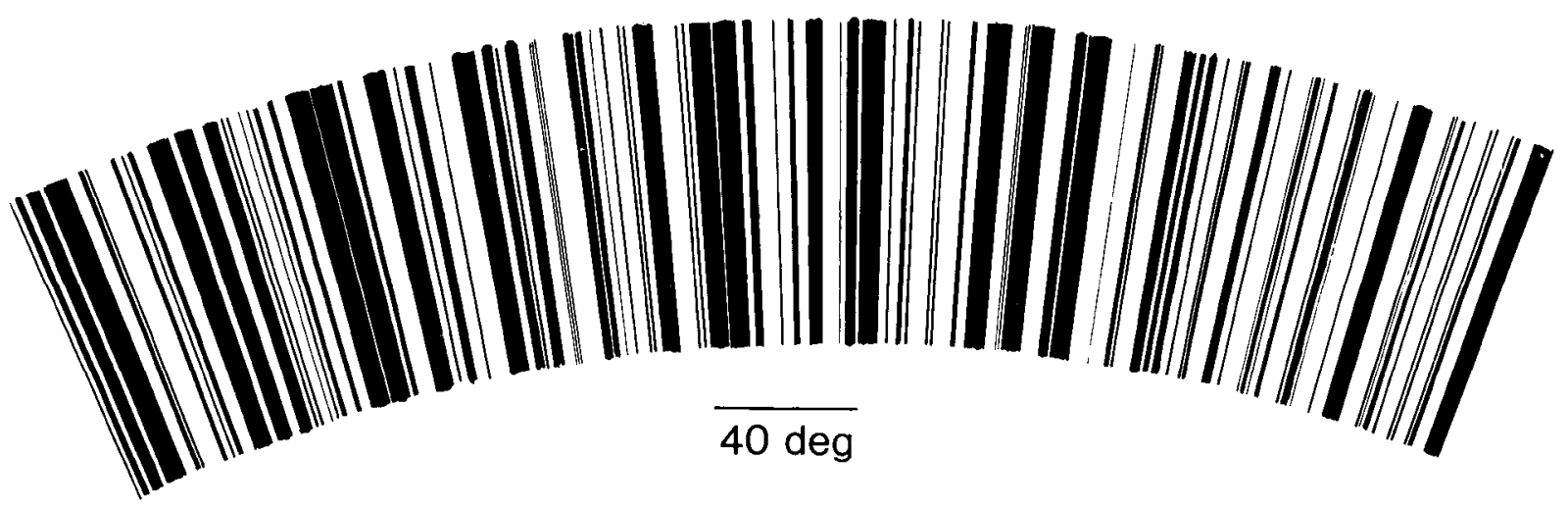

Figure 2. Grating pattern used for visual stimulation. The pattern consists of a pseudorandom sequence of white and black bars. Eight such sequences were mounted onto the edge of a plexiglass wheel that turned in the beam of a projector. At any one time, an area of $80^{\circ} \times 80^{\circ}$ was shown to the animal. This stimulation activated the entire binocular region of area 17 that extends more than $20^{\circ}$ into the contralateral visual field (Law et al., 1988). The scale bar indicates the size on the screen.

amounts of $\left[{ }^{14} \mathrm{C}\right] 2-D G$ were mixed with homogenized calf brain, and $20-\mu \mathrm{m}$-thick sections of the frozen brain paste were prepared in a refrigerated microtome in the same way as the brain slices. Brain paste slices were co-exposed with plastic radioactivity standards. Aliquots of each brain paste sample were dissolved first in $0.5 \mathrm{ml}$ tissue solubilizer (Protosol, New England Nuclear, Boston, MA) and then in $10 \mathrm{ml}$ scintillation fluid. Brain paste radioactivity was determined in the same scintillation counter as was used for measuring the plasma radioactivities to assure that tissue and plasma radioactivities were properly crosscalibrated.

Digitization of images. Autoradiograms on both films were digitized and analyzed on a microcomputer-based image analysis station consisting of a video camera (Dage MTI Series 68DX), an 8-bit frame grabber (Coreco, Montreal), an IBM-AT-compatible computer, and appropriate software (Image Calculator, developed by author H. Riml).

Compared to ${ }^{14} \mathrm{C}$ autoradiograms, individual ${ }^{3} \mathrm{H}$ radioactivity images contained a large amount of noise (Fig. 3). To decrease the noise associated with individual ${ }^{3} \mathrm{H}$ autoradiograms, 9-12 consecutive radioactivity images from supragranular layers $(0.15-0.45 \mathrm{~mm}$ cortical depth) were averaged. Images were aligned in each series of the autoradiograms with the help of holes pierced by a $25 \mathrm{G}$ needle into the tissue perpendicular to the cortical surface. Infragranular layers showed weak or no columnar pattern and were therefore not analyzed in this study. Alignment was carried out by interactively superimposing a life image of one autoradiogram onto an image of another already stored in memory and by simultaneously displaying the 2 images on a monitor. This procedure resulted in excellent alignment $\left(<0.1 \mathrm{~mm}\right.$ displacement). ${ }^{14} \mathrm{C}$ radioactivity images were averaged in the same way for the same brain slices.

Correction for metabolic and cross-contamination. The correction for the uptake of the first tracer occurring during the second stimulation (metabolic contamination) is described in the Appendix.

Optical densities for both films were converted to ${ }^{14} \mathrm{C}$ radioactivity images to eliminate errors due to incorrect cross-calibration between

Table 1. Orientations of grating used for stimulation in 2-DG experiments

\begin{tabular}{|c|c|c|c|}
\hline \multirow[b]{2}{*}{$\begin{array}{l}\text { Experi- } \\
\text { ment }\end{array}$} & \multicolumn{2}{|c|}{ Orientation $\left({ }^{\circ}\right)^{a}$} & \multirow{2}{*}{$\begin{array}{l}\text { Angle } \\
\text { between } \\
\text { orientations } \\
\left({ }^{\circ}\right) \\
\end{array}$} \\
\hline & $\begin{array}{l}\text { First } \\
\text { stimulation }\end{array}$ & $\begin{array}{l}\text { Second } \\
\text { stimulation }\end{array}$ & \\
\hline 250 & 0 & 90 & 90 \\
\hline 251 & 0 & -45 & 45 \\
\hline 252 & 0 & -20 & 20 \\
\hline 253 & 45 & -45 & 90 \\
\hline 257 & 0 & -45 & 45 \\
\hline 264 & 0 & 0 & 0 \\
\hline
\end{tabular}

"Clockwise, $0^{\circ}$ is vertical.
${ }^{3} \mathrm{H}$ and ${ }^{14} \mathrm{C}$ standards. ${ }^{3} \mathrm{H}$ radiation did not cause any visible blackening on the SB-5 film. Cross-contamination by ${ }^{14} \mathrm{C}$ radiation on the Ultrofilm was eliminated by subtracting the ${ }^{14} \mathrm{C}$ radioactivity image obtained on SB-5 film from the ${ }^{14} \mathrm{C}$-equivalent radioactivity image obtained on U1trofilm (Friedman et al., 1987; Juhler and Diemer, 1987) on a pixelby-pixel basis.

An example of the image calculation that corrects for metabolic and cross-contamination for 1 set of autoradiograms is shown in Figure 3.

Processing of cerebral activation images. Global changes in activation were minimized by unsharp masking. Cerebral activation images (Fig. $4, A, B)$ were first low-pass filtered using a filter kernel $16 \times 16$ pixels $(1 \times 1 \mathrm{~mm})$ wide. The filtered image (Fig. $4, C, D)$ was then subtracted from the original image to yield an image showing the columnar pattern on a relatively uniform background (Fig. $4, E, F$ ). The main spatial periodicity of the columnar pattern in these images was determined by 2-dimensional Fourier analysis.

To demonstrate the spatial relationship between the 2 activation patterns of each experiment, the $40 \%$ of the pixels that showed the highest values within a region of interest were labeled "activated" and the rest "not activated." The images shown in Figure 5 are overlaps of such binary images. The $40 \%$ threshold was chosen to reveal overlapping areas between the 2 activation patterns, especially in Experiments 251 and 257 , in which the difference between the 2 orientations was $45^{\circ}$ (Table 1).

Mapping eye-specific input with tritiated proline. In a separate experiment, 2 ferrets (Experiments 216 and 217) were each injected with 1.5 $\mathrm{mCi}$ of $\mathrm{L}-\left[2,3-{ }^{3} \mathrm{H}\right]$-proline under $2 \%-3 \%$ halothane anesthesia and aseptic conditions. The tracer was dissolved in 10-20 $\mu$ l sterile saline and intravitreally injected over a $20 \mathrm{~min}$ period through a $25 \mathrm{G}$ needle in-

Table 2. Amount of tracers injected and metabolic and crosscontamination on Ultrofilm for 2-DG experiments
Radioactivity $\begin{array}{ll}\text { Metabolic } & \text { detected } \\ \text { trapping of } & \text { on Ultro- }\end{array}$ $\begin{array}{lll}\text { Cross- } & \text { trapping of } & \text { on Ultro- } \\ \text { contami- } & \text { first tracer } & \text { film repre- }\end{array}$ nation by during senting ${ }^{14} \mathrm{C}$ on second second Ultrofilm stimulation stimulation

\begin{tabular}{|c|c|c|c|c|c|}
\hline \multirow[b]{2}{*}{$\begin{array}{l}\text { Experi- } \\
\text { ment }\end{array}$} & & \multirow{2}{*}{$\begin{array}{l}{ }^{14} \mathrm{C} \text { on } \\
\text { Ultrofilm } \\
(\%)\end{array}$} & \multirow{2}{*}{$\begin{array}{l}\text { second } \\
\text { stimulation } \\
(\%)\end{array}$} & \multirow{2}{*}{$\begin{array}{l}\text { second } \\
\text { stimulation } \\
(\%)\end{array}$} \\
\hline & {$\left[{ }^{3} \mathrm{H}\right] 2-\mathrm{DG}$} & $\begin{array}{l}{\left[{ }^{14} \mathrm{C}\right]} \\
2-\mathrm{DG}\end{array}$ & & & \\
\hline 250 & 5000 & 25 & 36 & 19 & 48 \\
\hline 251 & 5000 & 25 & 22 & 22 & 38 \\
\hline 252 & 5000 & 25 & 38 & 16 & 48 \\
\hline 253 & 5000 & 25 & 31 & 17 & 43 \\
\hline 257 & 4000 & 20 & 35 & 20 & 49 \\
\hline 264 & 3700 & 20 & 36 & 21 & 49 \\
\hline
\end{tabular}




\section{A}

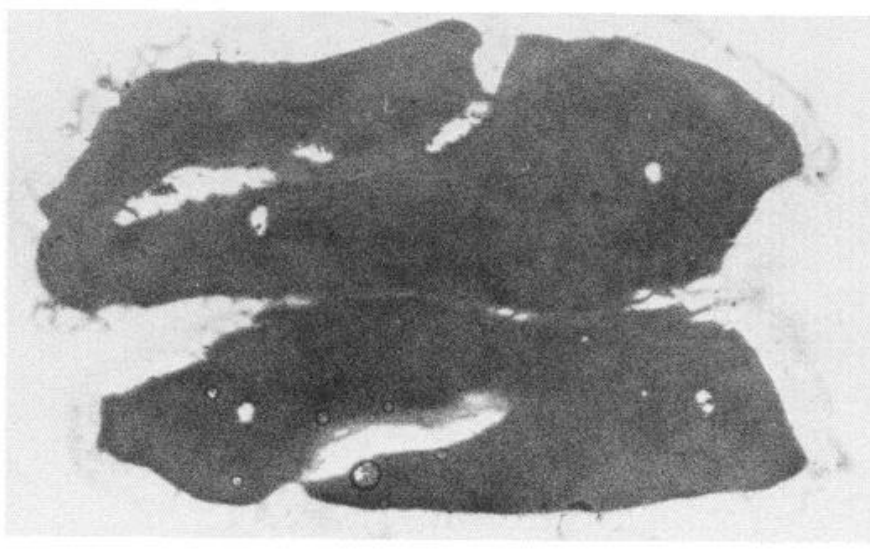

B



C



$5 \mathrm{~mm}$

Figure 3. Individual autoradiograms of a slice of flattened ferret visual cortex. The same slice was exposed to tritium-sensitive Ultrofilm $(A)$ and to Kodak SB-5 standard radiographic film (B; Experiment 253 ). The Ultrofilm autoradiogram $(A)$ shows the first and second stimulation to be about equally strong due to metabolic and ${ }^{14} \mathrm{C}$ cross-contamination (see Table 2). The orientations used for stimulation in Experiment 253 were orthogonal and elicited 2 roughly complementary activation pat- serted into the limbus of the left eye. The animals recovered from anesthesia and, in addition to standard care according to institutional guidelines, received daily intramuscular injections of chloramphenicol for $7 \mathrm{~d}$ to prevent eye infection.

Some clouding of the injected vitreous body was observed a few days after injection. This clouding was attributed to the injection of a relatively large amount of saline into the very small vitreous body of the ferret. The vitreal clouding would have interfered with visual stimulation through the injected eye. Moreover, stimulation through only 1 eye with moving gratings of changing orientations did not reliably elicit ocular dominance bands in the ferret. For these reasons, it was not possible to perform double-label experiments to demonstrate the overlap of ocular dominance and orientation columns.

The animals were killed by an overdose of pentobarbitol 12 and 20 $\mathrm{d}$ after injection. The occipital poles were processed for autoradiography as described above. Serial $30-\mu \mathrm{m}$-thick sections were exposed to tritiumsensitive Ultrofilm (LKB, Bromma, Sweden) for 3 months.

To obtain complete ocular dominance maps (Fig. 6), individual autoradiograms were projected onto a white sheet of paper, and the labeled regions were outlined with a fine pencil. Because the eye-specific projection pattern was not contained in its entirety in any one of the autoradiograms, the autoradiograms were projected consecutively until a composite image of the complete ocular dominance pattern was obtained. Composite images were redrawn with black ink and are shown in Figure 6.

In each composite image, the position of the tip of the lateral sulcus was marked. The shortest distance between the tip of the splenial sulcus and the area $17 / 18$ border was $2.3 \mathrm{~mm}(\mathrm{SD}, \pm 0.3 \mathrm{~mm} ; n=4)$. The angle between the area $17 / 18$ border and a straight line drawn through the lateral sulcus was $18^{\circ}\left(\mathrm{SD}, \pm 2^{\circ} ; n=4\right)$. These values were used as a reference to locate the area $17 / 18$ border in the 2-DG images (Fig. 5).

\section{Results}

\section{Double-label deoxyglucose autoradiography}

By ${ }^{3} \mathrm{H}$ standards, no detectable blackening of the SB-5 film was observed for the range of tissue radioactivities obtained in this study. In contrast, an average of $32 \%$ (range, $22 \%-38 \%$; Table 2) of the radioactivity detected on the Ultrofilm was caused by ${ }^{14} \mathrm{C}$ radiation.

Figure 1 shows the average normalized plasma radioactivity curves for the double-label experiments. Significant amounts of the first injected tracer remained in the plasma late in the experiment. As a consequence, the first tracer was available for metabolism during the second stimulation. Calculation of the $s$ value from Eq. (2) (see Appendix) shows that an average of 20\% (range, 16\%-22\%; Table 2 ) of the total tissue radioactivity measured for the first tracer at the end of the experiment was metabolically trapped in brain tissue during the second stimulation (metabolic contamination of the Ultrofilm radiographic image).

${ }^{14} \mathrm{C}$ cross-contamination and metabolic contamination together contributed an average of $45 \%$ (range, 38\%-49\%; Table 2) of the radioactivity detected on the Ultrofilm; that is, about half of the Ultrofilm image represents the cerebral activation pattern of the second stimulation.

Figure 3 shows a representative example of the autoradiograms (Fig. 3, $A, B$ ) and the activation image of the first period (Fig. $3 C$ ), which was derived by partially subtracting the ${ }^{14} \mathrm{C}$

terns (see Fig. $5 F$ ). The resulting autoradiogram in $A$ therefore shows relatively little patchiness. In contrast, the ${ }^{14} \mathrm{C}$ autoradiogram $(B)$ represents activation only by the second stimulation. The image shown in $C$ represents activation by the first stimulation; it was derived by a partial subtraction of the image shown in $B$ from the image shown in $A$ to correct for metabolic and ${ }^{14} \mathrm{C}$ cross-contamination on the Ultrofilm autoradiogram (Table 2). In the autoradiograms $(A, B)$, darker shades represent more radioactivity. In the metabolic activation image $(C)$, lighter shades represent more activation. 
A

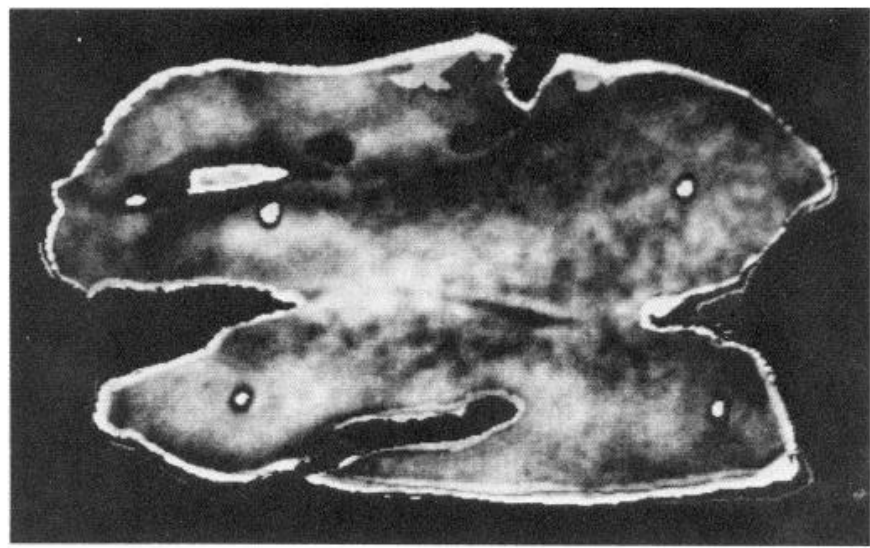

C

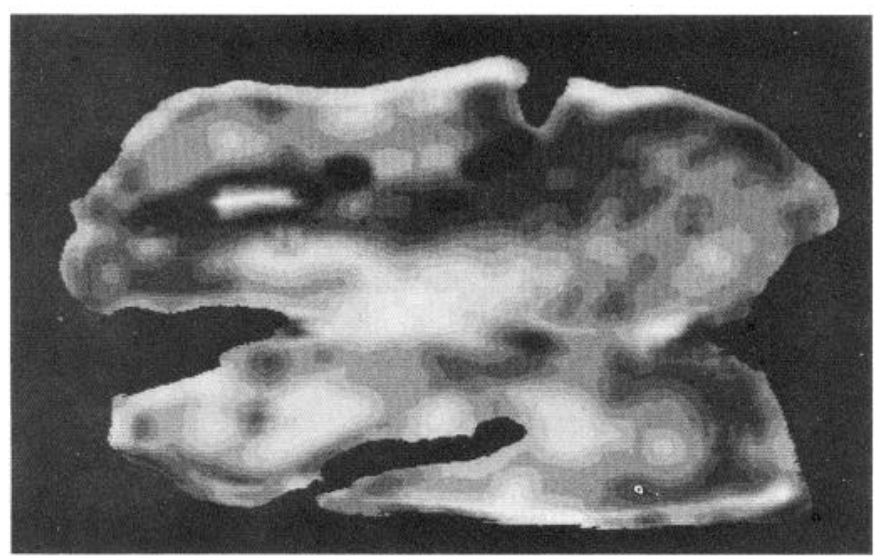

E

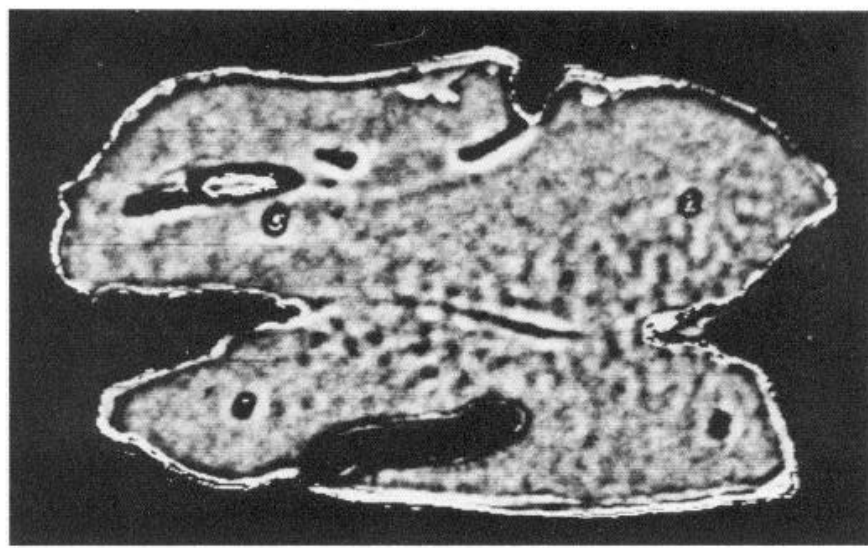

\section{B}

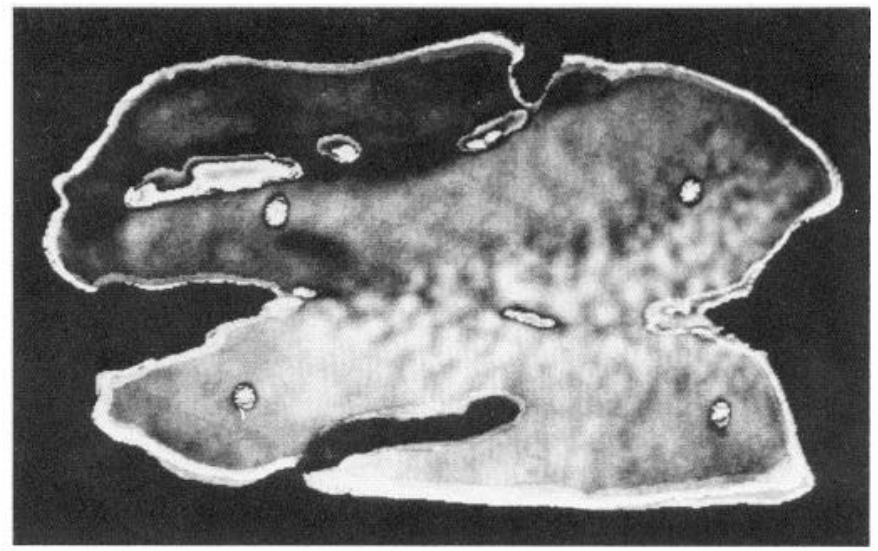

\section{D}

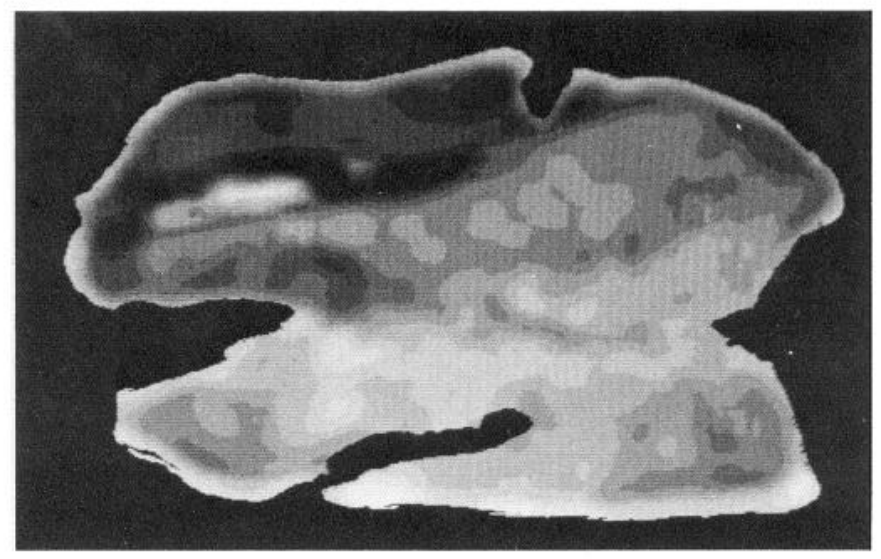

\section{F}



$5 \mathrm{~mm}$

Figure 4. Averaged activation image for the first $(A)$ and second stimulation $(B)$ of the ferret visual cortex (Experiment 253$)$. Each pattern is the average of 9-12 activation patterns aligned with the help of the 4 holes pierced perpendicularly into the cortical surface. Images shown in $A$ and $B$ were smoothed by a $1 \mathrm{~mm} \times 1 \mathrm{~mm}$ filter kernel. The smoothed images $(C, D)$ were subtracted from the images shown in $A$ and $B$ (unsharp masking) to yield the images shown in $E$ and $F$. The masked images show the activation patterns in area $17 / 18$ on a relatively homogeneous metabolic background. Lighter shades represent more activation. 


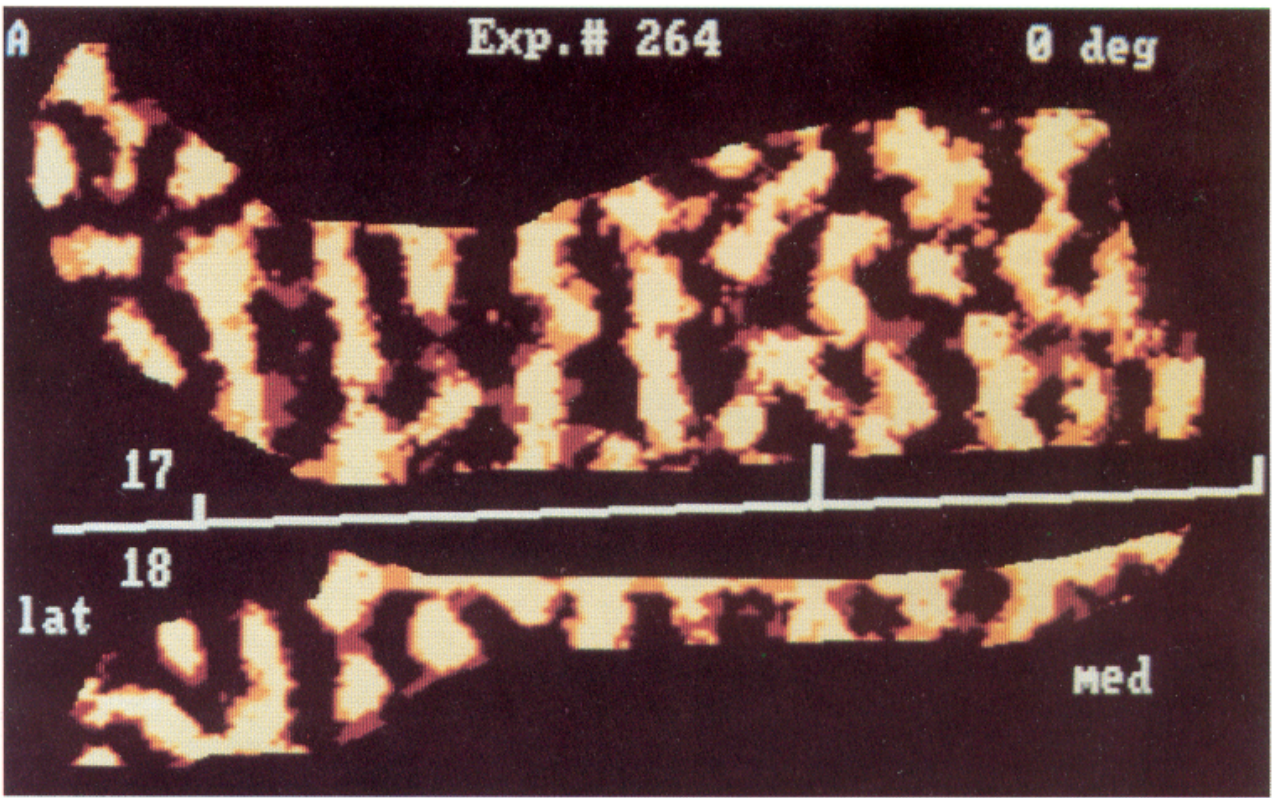

Figure 5. Overlap of regions representing 2 different orientations in the flattened visual cortical area 17/18 of the ferret. Colors indicate activation by the first stimulation (brown), second stimulation (yellow), both stimulations (white), and neither stimulation (black). Artifacts (incomplete flattening or holes used for alignment) and unstimulated regions were blackened. The experiment number and the angle between the 2 orientations used for the stimulation are given above each pattern. The arrows in $B$ indicate changes in orientational preference from vertical to oblique. The area $17 / 18$ border was identified by comparing the location of the lateral sulcus in each brain slice to that in the maps shown in Figure 6 (see Materials and Methods). Compared to Figure 6, the images in Figure 5 are rotated counter-clockwise $90^{\circ}$. The approximate elevations of the projection of the visual world at the vertical meridian (area 17/18 border; see scale bar) were estimated from the data in Law et al. (1988). The fixation point projects to about $-10^{\circ}$ elevation (Law et al., 1988). med, medial; lat, lateral; 17 , area $17 ; 18$, area 18 .


autoradiogram (Fig. $3 B$ ) from the ${ }^{3} \mathrm{H} /{ }^{14} \mathrm{C}$ Ultrofilm autoradiogram (Fig. 3A). This subtraction corrects for metabolic and cross-contamination.

Figure 4 shows averaged activation images for the first and second period of 1 experiment. The low-pass filtered images (Fig. 4, $C, D$ ) that were subtracted from the images shown in Figure $4, A$ and $B$, do not show any columnar pattern. The resulting masked images (Fig. $4, E, F$ ) show the columnar pattern on a relatively homogeneous background.
Visual cortical results

Organization of ferret visual cortical area $17 / 18$ in the orientational domain

Typical activation patterns corresponding to the 2 stimulations from a double-label experiment and their derivation by image processing are shown in Figures 3 and 4 . The mean periodicity of the orientation columns in this study was 1.4 cycles $/ \mathrm{mm}$. In all experiments, the columnar pattern seen in area 17 was in- 


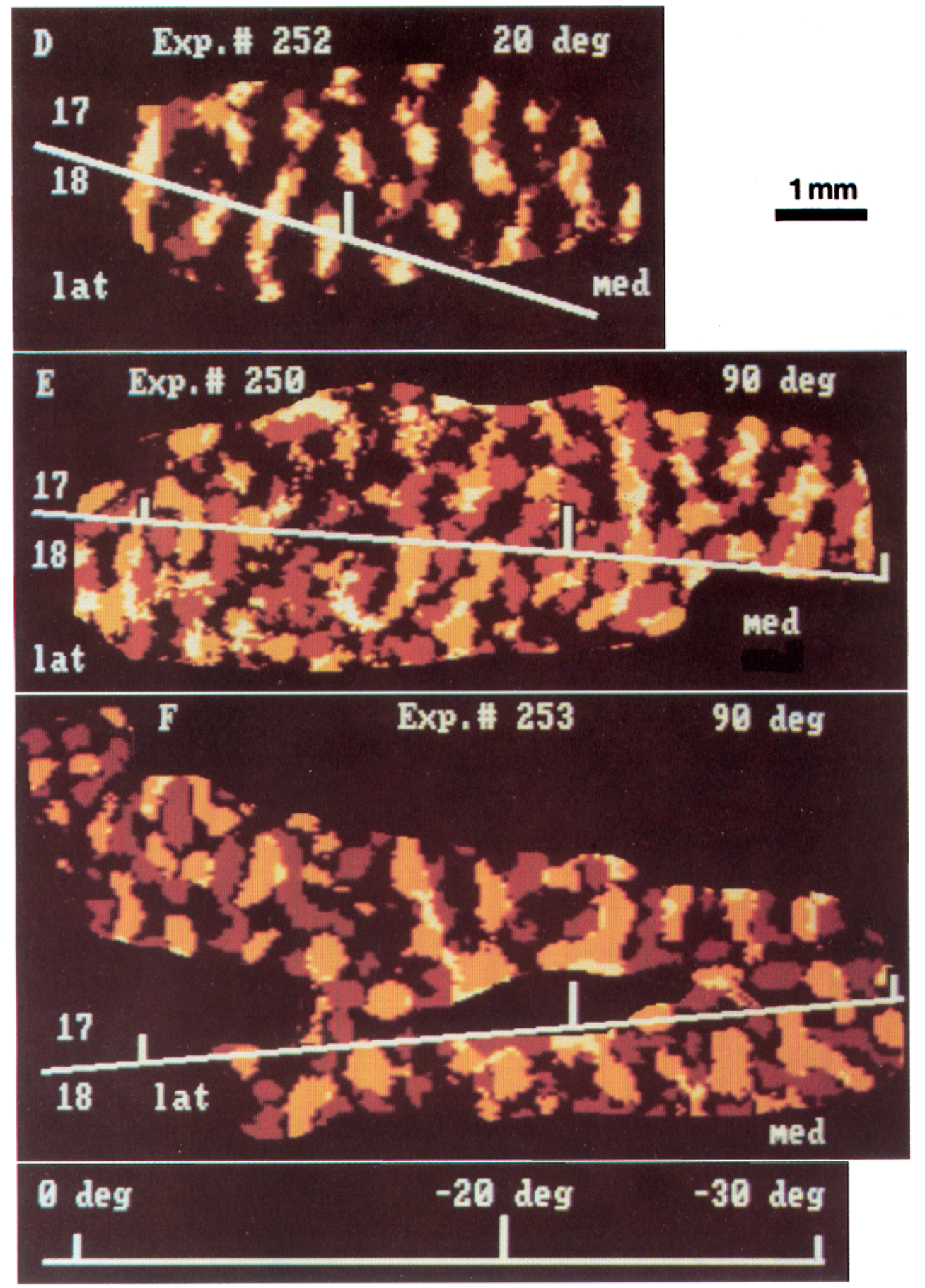

distinguishable from that in area 18. The orientational patches were often elongated and ran roughly orthogonal to the area 17/ 18 border (Figs. 4,5 ).

In Figure 5, color-coded maps show the overlap of the 2 activation patterns for all 6 ferrets. If the same orientation was used (Fig. $5 A$ ), the 2 activation patterns overlapped almost entirely. The remaining discrepancies were minor and likely represent residual noise, originating mainly from the activation pattern of the first stimulation, that is, from the intrinsically more noisy Ultrofilm autoradiogram (Fig. 3). When animals were stimulated with gratings of orthogonal orientations (Fig.
$5, E, F)$, patchy activation patterns were seen that were not fully complementary but did not overlap. In some regions, areas representing orthogonal orientations were immediately adjacent to each other; in others, they were separated by areas which were not activated by either stimulation.

With orientations forming an angle of $20^{\circ}$ (Fig. $5 D$ ) and $45^{\circ}$ (Fig. 5, B, C), complex patterns of partial overlap were seen. Relatively large areas were activated by either the first or the second stimulation. The degree of overlap of the two orientations was variable, ranging from nearly complete overlap in some areas to little overlap in others. Most regions of overlap 


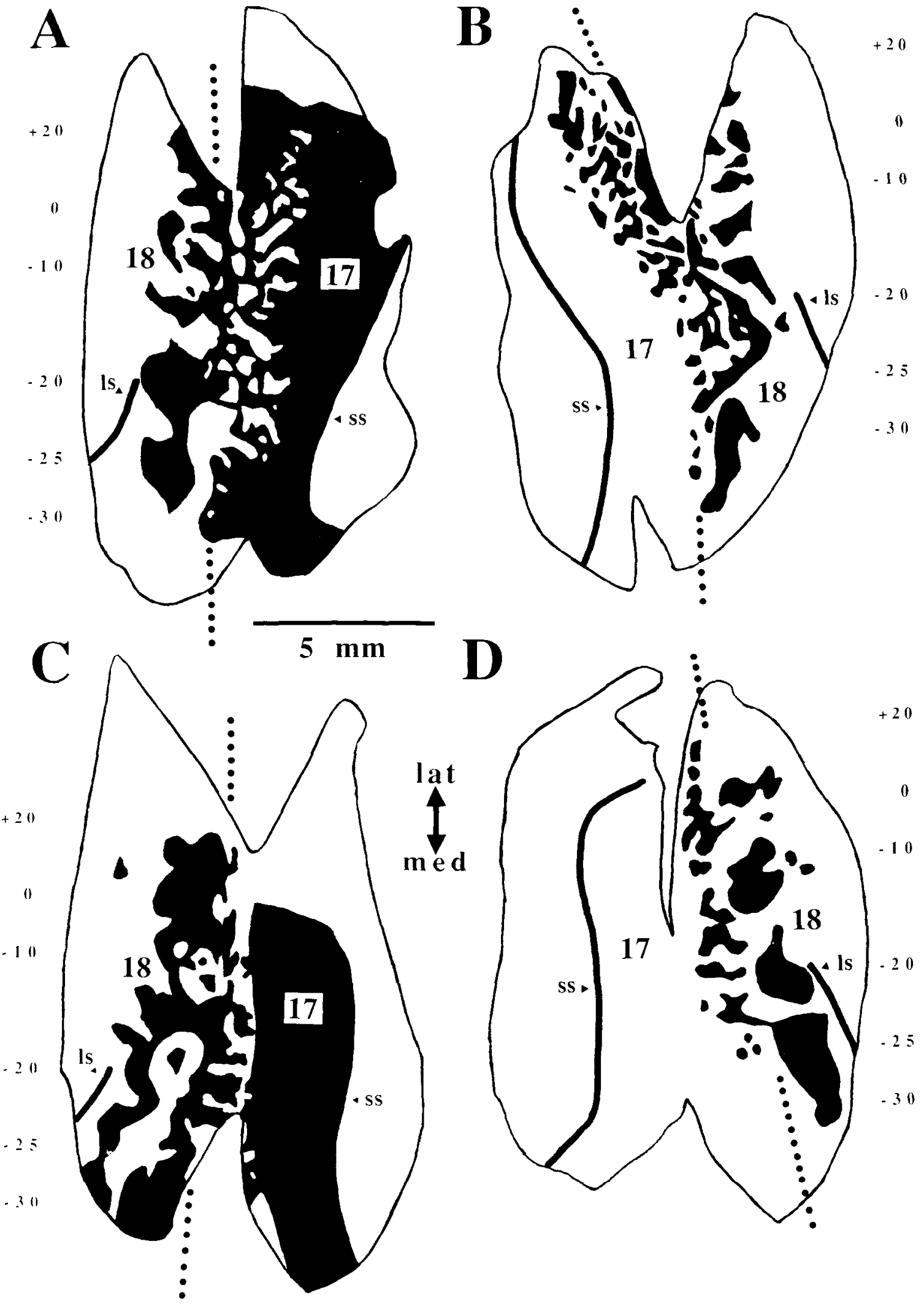

Figure 6. Composite ocular dominance maps of ferret visual cortex reconstructed from serial ${ }^{3} \mathrm{H}$-proline autoradiograms. $A$, Right cortex of ferret from Experiment 216 (contralateral to injected eye). $B$, Left cortex of ferret from Experiment 216 (ipsilateral to injected eye). $C$, Right cortex of ferret from Experiment 217 (contralateral to injected eye). $D$, Left cortex of ferret from Experiment 217 (ipsilateral to injected eye). Black areas represent regions that were radioactively labeled in the autoradiograms. The thin outlines delineate the margins of the brain sections. The thick lines indicate the position of the splcnial sulcus (ss) on the ventral surface apposing the cerebellum and of the lateral sulcus (ls) on the dorsal surface. The extensions of the dotted lines mark the approximate position of the area $17 / 18$ border (projection of the vertical meridian). The orientations of the slices (med, medial; lat, lateral) and of the visual field projected onto area 17/18 (Law et al., 1988) are shown. The point of the area 17/18 border closest to the tip of the lateral sulcus represents about $20^{\circ}$ of visual field elevation (Law et al., 1988). The approximate visual field elevations at the area $17 / 18$ border estimated from data by Law et al. (1988; their Figs. 1 and $17 B$ ) are given on the side of each panel. The fixation point projects to about $-10^{\circ}$ elevation (Law et al., 1988). The cortices displayed in $C$ and $D$ are not completely flattened at the occipital pole, resulting in only partial display of the binocular region of area 17. 
were surrounded by 3 or 4 regions which were each activated by only 1 of the stimulations. The arrows in Figure $5 B$ indicate the direction of the orientational changes. Reversals in the direction of the change from clockwise to counter-clockwise occurred frequently around any of the patches representing overlapping stimulations. These changes occurred on a scale smaller than the average periodicity of the orientation columns $(1.4$ cycles $/ \mathrm{mm}$ ).

\section{General organization of area $17 / 18$ in the ferret}

Figure 6 shows complete maps of the eye-specific input into area $17 / 18$ of the ferret. The maps represent the radioactive label in layer IV, the layer most prominently labeled by orthograde amino acid tracing of eye-specific input (Wiesel et al., 1974; Le Vay et al., 1985; McConnell and Le Vay, 1986; Löwel and Singer, 1987). Flattening of the occipital fold was not entirely successful in all cases and may have occurred at slightly different positions of the fold. Nevertheless, all preparations resulted in a separation of the 2 cortical sheets along the area $17 / 18$ border or the monocular/binocular border within area 17. Taken together, the maps provide a picture of eye-specific input to area $17 / 18$ in the ferret that is complete except for the part situated in the splenial sulcus (Law et al., 1988).

The contralateral projections (Fig. 6, $A$, C) uniformly laheled the area immediately rostral to the splenial sulcus on the tentorial surface of the occipital pole. This area is part of visual cortical area 17 and represents peripheral monocular regions of the visual field. In mustelides (McConnell and Le Vay, 1986; Le Vay et al., 1987; Law et al., 1988), the most peripheral receptive fields (up to $130^{\circ}$ ) are located in the depth of the splenial sulcus that was not flattened in this study.

As the cortex wraps around the occipital pole, layer IV was labeled in a patchy fashion (Fig. 6, $A, C$ ). This segment corresponds to the binocular segment of area 17 , and extends more than $20^{\circ}$ into the periphery in the ferret (Law et al., 1988) and $40^{\circ}$ in the mink (McConnell and Le Vay, 1986). It was the approximate area stimulated in the $2-\mathrm{DG}$ experiments by the visual stimulus (total area, $80^{\circ} \times 80^{\circ}$ ).

The region rostral to area 17 was less heavily labeled and had a much coarser pattern of labeled and unlaheled regions; it is area 18 . No uniformly labeled region similar to that seen in area 17 was found in area 18 . The rostral border of area 18 runs in a medio-lateral direction and partially coincides with the lateral sulcus. A separate area 19 could not be identified on the proline autoradiograms.

\section{Ocular dominance pattern in the binocular segments of area $17 / 18$}

Figure 6 shows that, in the binocular segment of area 17, ipsilateral projections form islands in an almost completely contiguous pattern of contralateral stripes. Some of the islands are elongated and have more than 1 lobe, as if a few patches became confluent (e.g., see Fig. 6B). The same global arrangement was found in area 18 . However, in area 18, the patches wcrc about $2 \mathrm{~mm}$ apart; in area 17 , they were about $0.7 \mathrm{~mm}$ apart.

The island/stripe pattern does not seem to have any particular orientation. Although some islands/stripes are oriented orthogonal to the $17 / 18$ border, many others run in parallel or obliquely. When the width of the labeled ipsilateral islands (Fig. 6, $B$, $D$ ) is compared to that of the labeled contralateral stripes (Fig. $6, A, C)$, the islands are narrower than the contralateral stripes. The total area occupied by the islands is smaller than that oc- cupied by the stripes in the binocular segment of area $17 / 18$. Towards the border from the monocular to the binocular segment of area 17, the ipsilateral islands seem to thin out.

In the ferret, the lower visual world projects progressively more medially along the area $17 / 18$ border, which coincides with the vertical mcridian (Law et al., 1988). Figure 6 shows that, in area 18 , the ipsilateral patches are larger medially than laterally. Moreover, the ipsilateral projections occupy a larger portion of area 18 medially than laterally. A similar difference between the medial and lateral regions is seen for area 17 in Figure $6 \mathrm{~A}$, where the holes in the contralateral projection become smaller and seem less elongated in the region close to the $0^{\circ}$ elevation point.

\section{Discussion}

\section{Methodological considerations}

The conventional (single-label) 2-DG method (Sokoloff et al., 1977) provides a valuable tool to study the functional organization of complex activation patterns in the sensory brain of mammals, for example, in the visual system (Kennedy et al., 1976; Hubcl ct al., 1977), in the olfactory system (Sharp et al., 1975), in the somatosensory system (Durham and Woolsey, 1977; Juliano and Whitsel, 1987), and in the auditory system (Webster et al., 1978). $\left[{ }^{3} \mathrm{H}\right]-$ or $\left[{ }^{14} \mathrm{C}\right] 2-\mathrm{DG}$ autoradiograms of $20-\mu \mathrm{m}$-tissue sections can be obtained from virtually every brain structure and provide excellent spatial resolution.

The major disadvantage of the conventional 2-DG method is that cerebral activation can only be mapped once in each animal. A number of double-label deoxyglucose methods have therefore been proposed to map 2 activations in the same animal (Livingstone and Hubel, 1981; Olds et al., 1985; John et al., 1986; Friedman et al., 1987). These methods have been criticized (Webster et al., 1983; Redies et al., 1987; Friedman et al., 1989) because they neglect the fact that the tracer injected first is also available for metabolic trapping during the second stimulation (Fig. 1, Table 2). A quantitative solution to this problem (Redies ct al., 1987; Redies and Diksic, 1989b) is applied in this study [Eqs. (1), (2); see Appendix]. The tracer kinetic model, the experimental rationale, and the parameters for this approach have been described in detail elsewhere (Redies et al., 1987; Redies, 1988; Redies and Diksic, 1989a, b; Redies and Gjedde, 1989; Redies et al., 1989).

The present study shows that, with the appropriate corrections, complex cerebral activation images representing 2 sequential visual stimulations can be metabolically mapped using $\left[{ }^{3} \mathrm{H}\right] 2-\mathrm{DG}$ and $\left[{ }^{14} \mathrm{C}\right] 2-\mathrm{DC}$ as tracers. The corrections eliminate (1) metabolic contamination, that is, metabolic trapping of the first tracer during the second stimulation; and (2) cross-contamination between the 2 tracers on the radiographic films.

As outlined in detail above (see Materials and Methods), the following strategies were used to minimize the errors associated with image processing and image calculations:

(1) Two hundred times more ${ }^{3} \mathrm{H}$ than ${ }^{14} \mathrm{C}$ was injected (Table 2 ). With this ratio, about one third of the radioactivity detected on the Ultrofilm is caused by ${ }^{14} \mathrm{C}$ radiation (Table 2 ). While higher ratios result in less cross-contamination, the amount of tritiated 2-DG injected was limited by the cost of the tracer.

(2) To decrease the experimental errors and the amount of the first tracer taken up during the second experimental period (Table 2; Redies el al., 1987; Redies and Diksic, 1989b), the second period was relatively short $(30 \mathrm{~min})$; the first period was 
relatively long $(60 \mathrm{~min})$ to permit the levels of the first tracer in plasma to fall to low levels (Fig. 1).

(3) Autoradiograms on both films were calibrated to the same set of ${ }^{14} \mathrm{C}$ radioactivity standards, thus eliminating errors caused by incorrect cross-calibration of ${ }^{3} \mathrm{H}$ and ${ }^{14} \mathrm{C}$ radioactivities.

(4) The noise associated with the intrinsically more noisy ${ }^{3} \mathrm{H}$ autoradiograms (Fig. 3) was reduced by averaging 9-12 radioactivity images from supragranular layers.

(5) To minimize errors contributed by incorrect cross-calibration between the 2 films and between the 2 plasma radioactivity curves, $s$ values were calculated by using the radioactivities measured for the unstimulated frontal cortex to normalize radioactivities for the visual cortex [Eqs. (1), (2); see Appendix].

\section{General layout of ferret visual area 17/18 (proline study)}

The general layout of area $17 / 18$ in flattened ferret visual cortex (Fig. 6) resembles that previously reconstructed by single-cell recording and neuroanatomical techniques in the ferret (Law et al., 1988) and in the mink (McConnell and Le Vay, 1986; Le Vay et al., 1987). The apparent absence of a monocular segment in area 18 agrees with neurophysiological data from the mink and ferret (McConnell and Le Vay, 1986; Le Vay et al., 1987; Law et al., 1988).

Because the sectioning and mounting procedure used in the proline study was the same as that used in the double-label 2-DG experiments, the maps of eye-specific input shown in Figure 6 can be transferred to the 2-DG maps (Fig. 5) using the position of the lateral and splenial sulcus as anatomical landmarks (see Materials and Methods).

\section{Organization in the orientational domain}

The orientation pattern (Figs. 4,5 ) and its periodicity in the ferret visual cortex $(1.4$ cycles $/ \mathrm{mm})$ are similar to those seen in the macaque (Hubel et al., 1977; Tootell et al., 1988) and in the cat (Singer, 1981; Albus and Sieber, 1984; Löwel and Singer, 1987). The ferret, cat, and macaque patterns appear patchy, whereas the tree shrew pattern consists of more regular bands running in parallel with occasional branching points (Humphrey et al., 1980). Like in the cat (Singer, 1981; Albus and Sieber, 1984; Löwel et al., 1987) and the tree shrew (Humphrey et al., 1980), the patches in the ferret visual cortex are elongated and generally run orthogonal to the area $17 / 18$ border, with little difference between areas 17 and 18 .

Figure 5 provides information on the representation of more than the 2 orientations used for stimulation in each experiment. For example, the extensive areas of overlapping activation seen in Figure $5, B-D$, are likely to represent orientations intermediate to the 2 orientations used in the stimulation because individual visual cortical neurons in the carnivores (cat: Albus, 1975; mink: Le Vay et al., 1987) are responsive to a range of orientations (median half-width range, $\sim 20-30^{\circ}$ ). Moreover, at a given cortical location, neurons have a similarly wide range of optimal orientations (Albus, 1975). In agreement with these data, the overlap is extensive in Figure $5, B$ and $C\left(45^{\circ}\right.$ difference between orientations), but sparse in Figure 5, $E$ and $F\left(90^{\circ}\right.$ difference). The areas not activated by either stimulation in Figure 5 (black areas) likewise represent orientations complementary to those used in the experiment because the carnivore visual cortex is not known to have regions lacking orientationselective cells, such as the cytochrome oxidase patches of the primate visual cortex (Livingstone and Hubel, 1984).

\section{Comparison of 2-DG maps with results from other mapping studies}

In the following, the results obtained in the present 2-DG study are compared with results from electrophysiological mapping studics in cat visual cortex (Swindale et al., 1987) and optical imaging studies in macaque visual cortex (Blasdel and Salama, 1986).

\section{Similarities between the studies}

Despite differences, there are several similarities between the 2-DG results and other mapping studies (Blasdel and Salama, 1986; Swindale et al., 1987). These similarities are: (1) frequent changes in the direction of the orientational gradient, (2) frequent changes in the steepness of the directional gradient, and (3) representation of any orientation in both relatively large and small patches.

Interestingly, it is these features that are also seen in orientation maps generated by computer simulations (Swindale, 1982; Linsker, 1986). In particular, some of the orientation maps obtained in the present study (e.g., Fig. 5, B, C) look strikingly similar to maps gencratcd in the computer simulations by Linsker (1986). In addition to the general features mentioned above, orientational patches in both Linsker's map and the maps shown in Figure 5 are typically flanked on 2 of 4 sides by patches representing neighboring orientations and on the other 2 sides by patches representing the opposite orientation, in a crosshatch pattern.

The resemblance of experimentally obtained and computergenerated maps is of conceptual significance. The computer simulations are based on relatively simple principles governing the development of synaptic strength between the modules (Swindale, 1982; Linsker, 1986). The resemblance supports the suggestion that basic developmental mechanisms may also induce the complex arrangement of orientation columns in vivo (von der Malsburg, 1973; Swindale, 1980, 1982; von der Malsburg and Cowan, 1982; Linsker, 1986).

\section{Differences in experimental uncertainties between studies}

Because each of the different methods is associated with uncertainties and perhaps artifacts, it is important to carefully compare results obtained by the different methods before drawing conclusions about cortical functional organization.

Swindale et al. (1987) used interpolation paradigms in conjunction with single electrode recordings to obtain orientation maps. These authors estimated that the error in localizing the border of orientational domains associated with the interpolation is, on the average, about $200 \mu \mathrm{m}$. In view of this uncertainty, some of the details in cortical organization shown in their maps derived not solely from experimental data but also from the assumptions on which the interpolation procedure was based. This may be especially problematic at points where steep changes in the orientational gradient occurred.

The methodology applicd in the present study is based on a set of assumptions that relate to glucose metabolism (Sokoloff et al., 1977; Redies et al., 1987; Redies and Diksic, 1989a, b; Redies and Gjedde, 1989). These assumptions are less likely to directly bias results on functional cortical organization than an interpolation paradigm. The sampling density is much higher in the 2-DG maps that have a spatial resolution of $50-100 \mu \mathrm{m}$. The 2-DG miaps therefore provide a spatially very detailed picture for the 2 orientations mapped in each study. 
Optical imaging provides excellent spatial resolution and allows the mapping of many different activation patterns in the same animal. However, the physiological interpretation of optical imaging data is difficult because the physiological correlates of the signals detected are largely unknown (see below).

\section{Differences in signals detected}

The orientation maps obtained by optical imaging, electrophysiology, and the 2-DG method may also differ because of differences in the signals detected. The signals detected by the 2-DG method arc wcll understood and easily quantified (Sokoloff et al., 1977; Redies et al., 1987; Redies and Gjedde, 1989). Their physiological correlates are the inhibitory and excitatory synaptic activity (reviewed in Nudo and Masterton, 1986). The signals detected by electrophysiological recording of cellular discharge are also well understood. In contrast, it is at present unknown what the signals optically detected in the intact mammalian brain are and how they relate to synaptic activity or cellular discharge. If the signals are of multiple origin (Grinvald et al., $1986,1988)$, they may not all change in the same direction upon cerebral activation. The physiological interpretation of optical imaging data therefore remains problematic.

Despite these differences, good correlations between neuronal discharge on the one hand and the 2-DG or optical signals on the other hand were reported for the visual cortex (Schoppmann and Stryker, 1981; Blasdel and Salama, 1986; Grinvald et al., 1986, 1988). Neverthcless, clcctrophysiological sampling in these studies was not dense enough to draw firm conclusions about the equivalence of the different methods, especially for regions in which the orientational gradient is steep.

\section{Breaks, modules, and singularities}

The orientation maps obtained by Blasdel and Salama (1986) in the macaque visual cortex revealed striking discontinuities (breaks) in the orientational gradient surrounding individual cortical "modules." The possibility has been raised that these breaks and modules are experimental artifacts (van Essen and Orbach, 1986; Grinvald et al., 1986). The maps of Swindale et al. (1987) do not show such discontinuities. In the ferret maps (Fig. 5, $E, F$ ), frequent discontinuities are seen where orthogonal orientations are represented immediately adjacent to one another.

In the ferret visual cortex, patches representing 1 orientation often are elongated and extend over a distance across the cortical surface about 2 to 3 times greater than the average periodicity of the patches (Fig. 5). These results indicate that the ferret visual cortex is not as neatly organized into relatively small and round functional modules, as the macaque visual cortex seems to be (Blasdel and Salama, 1986). These differences may reflect methodological differences (see above), as well as species differences. In particular, the cylochrome oxidase palches of the monkey visual cortex, which lack orientation-selective cells (Livingstone and Hubel, 1984), are not found in nonprimate species such as the ferret.

Another feature seen in orientation maps are "singularities," points around which all orientations are arranged in an orderly fashion (Linsker, 1986; Swindale et al., 1987). Singularities are spaced at regular intervals in the map by Swindale et al. (1987) and perhaps are a consequence of the assumption that there are no discontinuities in the interpolated maps. The computational maps by Linsker (1986) show a continuous spectrum, from singularities, to points surrounded by a few but not all orientations, to steep orientational changes that occur along a straight line. Similarly, in the 2-DG maps (Fig. 5), there are occasional points surrounded by several orientations, but these are less frequent than points in which 2 neighboring orientations lie side by side.

\section{Ocular dominance pattern in binocular segments of area $17 / 18$}

The island/stripe pattern found in area $17 / 18$ of the ferret (Fig. 6 ) is similar to data from the mink (McConnell and Le Vay, 1986) and has previously becn seen in the ferret, though perhaps less clearly (Law et al., 1988).

The ocular dominance pattern of the cat assumes the appearance of irregularly intertwined beads on a string (Löwel and Singer, 1987; Anderson et al., 1988). As in the ferret, the contralateral projections in the cat are more prominent than the ipsilateral ones, but this imbalance is less striking than the imbalance seen in the ferret. Both the cat pattern (Löwel and Singer, 1987; Anderson et al., 1988) and the ferret pattern (Fig. 6) have a similar periodicity and do not show any particular orientational preference.

Unlike the cat and ferret patterns, the ocular dominance pattern in the macaque consists of elongated stripes lying next to each other, with occasional branching points (Hubel and Wiesel, 1978; Le Vay et al., 1985). In the macaque, these stripes are oriented orthogonally to the area $17 / 18$ border.

At present, the functional significance of these species differences remains unknown. It is also unclear whether these differences reflect differences in the intracortical mechanisms causing segregation of eye-specific input or differences in the afferent projections.

The relative prominence of the ipsilateral projections in the more medial (lower visual field) regions of the ferret area 18 (Fig. 6) can also be seen in a figure published previously for the ferret (Law et al., 1988; their Fig. 15). To our knowledge, the ferret is the first species for which changes in the ocular dominance pattern of area 18 along the vertical visual axis have been described. Area 17 does not show a similarly strong change, though, at least in Figure $6 \mathrm{~A}$, the holes in the contralateral projection are smaller around the location of the foveal projection ( $-10^{\circ}$ elevation; Law et al., 1988). Patches also seem to become smaller and less elongated around the projection of the fixation point in one of the orientation maps (see Fig. $5 F$ ), but this feature is not confirmed by the other maps in Figure 5.

Like in the macaque (Le Vay et al., 1985), the ipsilateral islands in area 17 of the ferret become narrower as they approach the monocular fragment (Fig. 6). The number of contralaterally driven units was found to increase towards the periphery in the ferret (Law et al., 1988).

These results bear upon the possible developmental mechanisms eliciting segregation of eye-specific input to area $17 / 18$ in the ferret. It has been shown in computer simulations that an imbalance in the effectiveness of competition leads to a pattern in which the less effective feature forms islands surrounded by the more effective feature (Swindale, 1980). Similar island/ stripe patterns can also be obtained by local activator/inhibitor models in which the inhibition is either stronger or weaker than the activation (Young, 1984). The similarity of the pattern in areas 17 and 18 , despite the difference in periodicity, suggests that the mechanism(s) causing segregation of eye-specific input are the same in both areas but have different space or time constants. 
For technical reasons, we were unable to study the overlap of orientation and ocular dominance patterns. However, our results suggest that the relationship between ocular dominance and orientation columns must be different in areas 17 and 18 (if there is a simple relationship at all) because the orientation pattern is very similar in areas 17 and 18 but the ocular dominance pattern has a different periodicity.

\section{Appendix}

Whereas the radioactivity image produced by the second $\operatorname{tracer}\left(\left[{ }^{14} \mathrm{C}\right] 2\right.$ DG) represents the cerebral activation image for the second stimulation, the image produced by the first tracer $\left(\left[{ }^{3} \mathrm{H}\right] 2-\mathrm{DG}\right)$ represents a weighted mixture of the cerebral activations elicited during both stimulations (Redies et al., 1987; Redies and Diksic, 1989b) because the first tracer is available for metabolic trapping during both stimulations (see Table 2). The cerebral activation image representing the first stimulation was recovered by partially subtracting the radioactivity image obtained for the second tracer from the radioactivity image of the first tracer. This subtraction corrects for uptake of the first tracer during the second stimulation (Redies et al., 1987; Redies and Diksic, 1989b).

Cerebral functional activity for the first stimulation is proportional to glucose utilization for the first period of the experiment $\left[R\left(T_{0} \rightarrow T_{1}\right)\right]$. It has been shown (Redies and Diksic, 1989b) that

$$
R\left(T_{0} \rightarrow T_{1}\right) \propto C^{*}{ }_{i\left(T_{2}\right)}-s \times C^{* *}{ }_{i\left(T_{2}\right)},
$$

wherc $C^{*}{ }_{i\left(T_{2}\right)}$ and $C^{* *}{ }_{i\left(T_{2}\right)}$ are the radioactivitics of the tracers measured at the time of decapitation, $T_{2}{ }^{*}$ and ${ }^{* *}$ denote parameters of the first and second tracer, respectively; $s$ is a constant (Redies and Diksic, 1989b). $\propto$ denotes proportionality. In this study, $s$ was calculated according to Eq. (B17) in Redies et al. (1987):

$$
s=\frac{I P^{*}\left(T_{1} \rightarrow T_{2}\right)}{I P^{*}\left(T_{0} \rightarrow T_{2}\right)} \times \frac{C_{i_{N}\left(T_{2}\right)}^{*}-C_{E\left(T_{2}\right)}^{*}}{C^{* *}{ }_{i N\left(T_{2}\right)}-C^{* *}{ }_{E\left(T_{2}\right)}},
$$

where $I P^{*}\left(T_{1} \rightarrow T_{2}\right)$ and $I P^{*}\left(T_{0} \rightarrow T_{2}\right)$ are the specific precursor activities of the first tracer that were integrated from the start of the experiment $\left(T_{0}\right)$ to the injection of the second tracer $\left(T_{1}\right)$, and from $T_{0}$ to the time of decapitation $\left(T_{2}\right)$, respectively; $C^{*}{ }_{i_{N}\left(T_{2}\right)}$ and $C^{* *}{ }_{i_{N}\left(T_{2}\right)}$ are the radioactivities measured for the frontal cortex (control values) at time $T_{2}$; and $C^{*}{ }_{E\left(T_{2}\right)}$ and $C^{* * *}{ }_{E\left(T_{2}\right)}$ are the radioactivitics calculated for the precursor compartment at time $T_{2}$ (Redies et al., 1987). By normalizing radioactivities for the visual cortex to those of unstimulated frontal cortex [Eq. (2)], potential errors due to incorrect cross-calibration of the ${ }^{14} \mathrm{C}$ radioactivities between the 2 films are minimized because any mistake is made twice (for the visual and frontal cortex) and largely cancels out in Eq. (1). Moreover, both films are calibrated to the same set of ${ }^{14} \mathrm{C}$ radioactivity standards, thus eliminating errors introduced by incorrect cross-calibration between ${ }^{14} \mathrm{C}$ and ${ }^{3} \mathrm{H}$ radioactivity standards. Correct calibration of the ${ }^{3} \mathrm{H}$ standards is particularly problematic due to the short range of ${ }^{3} \mathrm{H}$ radiation in tissue $(\sim 3 \mu \mathrm{m})$. The conversion of ${ }^{3} \mathrm{H}$ to ${ }^{14} \mathrm{C}$ radioactivity is based on the constant relationship between the 2 isotopes for a wide range of film blackening (Juhler and Diemer, 1987; Friedman et al., 1987).

Before calculating $s$, the ${ }^{3} \mathrm{H}$ plasma radioactivity valucs were converted to ${ }^{14} \mathrm{C}$ equivalents by multiplication of the ${ }^{3} \mathrm{H}$ values with the approximate ${ }^{14} \mathrm{C} /{ }^{3} \mathrm{H}$ conversion factor for Ultrofilm $(0.015$; Friedman et al. 1987). Inaccuracies in this conversion lead to very small errors in calculating $s$ from Eq. (2) because it can be shown that $C_{E\left(r_{2)}\right)}^{*}$ is less than $10 \%$ of $C^{*},(T$, at $90 \mathrm{~min}$ after injection in the ferret experiments (Redies and Gjedde, 1989) and because $I P^{*}\left(T_{1} \rightarrow T_{2}\right)$ and $I P^{*}\left(T_{0} \rightarrow T_{2}\right)$ form a ratio. The $s$ value was calculated with the computer program DOUBLE (Redies, 1988, 1989) using the average ferret gray matter rate constants of the $K_{1}^{*}-k_{4}{ }^{*}$ model (Redies et al., 1989). An example of this image calculation is shown for 1 set of autoradiograms in Figure 3.

\section{References}

Albus K (1975) A quantitative study of the projection area of the central and paracentral visual field in area 17 of the cat. II. The spatial organization of the orientation domain. Exp Brain Res 24:181-202. Albus K, Sieber B (1984) On the spatial arrangement of iso-orientation bands in the cat's visual cortical areas 17 and 18 : a $\left[{ }^{14} \mathrm{C}\right]$ deoxyglucose study. Exp Brain Res 56:384-388.

Anderson PA, Olavarria J, van Sluyters RC (1988) The overall pattern of ocular dominance bands in cal visual cortex. J Neurosci 8:21832200.

Blasdel GG, Salama G (1986) Voltage-sensitive dyes reveal a modular organization in monkey striate cortex. Nature 321:579-585.

Cucchiaro J, Guillery RW (1984) The development of the retinogeniculate pathway in normal and albino ferrets. Proc R Soc Lond [Biol] 223:141-164.

Durham D, Woolsey TA (1977) Barrels and columnar cortical organization: evidence from 2-deoxyglucose (2-DG) experiments. Brain Res 137:169 174.

Friedman HR, Bruce CJ, Goldman-Rakic PS (1987) A sequential double-label ${ }^{14} \mathrm{C}$ and ${ }^{3} \mathrm{H}-2-\mathrm{DG}$ technique: validation by double-dissociation of functional states. Exp Brain Res 66:543-554.

Friedman HR, Bruce CJ, Goldman-Rakic PS (1989) Resolution of metabolic columns by a double-label 2-DG technique: interdigitation and coincidence in visual cortical areas of the same monkey. J Neurosci $9: 4111-4121$.

Grinvald A, Lieke E, Frostig RD, Gilbert CD, Wiesel TN (1986) Functional architecture of cortex revealed by optical imaging of intrinsic signals. Nature 324:361-364

Grinvald A, Frostig RD, Lieke E, Hildesheim R (1988) Optical imaging of neuronal activity. Physiol Rev 68:1285-1366.

Hubel DH, Wiesel TN (1978) Anatomical demonstration of orientation columns in macaque monkey. $\mathbf{J}$ Comp Neurol 177:361-380.

Hubel DH, Wiesel TN, Stryker MP (1977) Orientation columns in macaque monkey visual cortex demonstrated by the 2-deoxyglucose autoradiographic technique. Nature 269:328-330.

Humphrey AL, Skeen LC, Norton TT (1980) Topographic organization of the orientation column system in the striate cortex of the tree shrew (Tupaia glis). II. Deoxyglucose mapping. J Comp Neurol 192:549-566.

Jackson CA, Peduzzi JD, Hickey TL (1989) Visual cortical development in the ferret. I. Genesis and migration of visual cortical neurons. J Neurosci 9:1242-1253.

John ER, Tang Y, Brill AB, Young R, Ono K (1986) Double-labeled metabolic maps of memory. Science 233:1167-1175.

Juhler M, Diemer NH (1987) A method for ${ }^{14} \mathrm{C}$ and ${ }^{3} \mathrm{H}$ double-label autoradiography. J Cereb Blood Flow Metabol 7:572-577.

Juliano SC, Whitsel BL (1987) A combined 2-deoxyglucose and neurophysiological study of primate somatosensory cortex. J Comp Neurol 263:514-525.

Kennedy C, DesRosiers MH, Sakurada O, Shinohara M, Reivich M, Jehle JW, Sokoloff L (1976) Metabolic mapping of the primary visual system of the monkey by means of the autoradiographic ${ }^{14} \mathrm{C}$ deoxyglucose technique. Proc Natl Acad Sci USA 73:4230-4234.

Law MI, Zahs KR, Stryker MP (1988) Organization of primary visual cortex (area 17) in the ferret. J Comp Neurol 278:157-180.

Le Vay S, Connolly M, Houde J, Van Essen DC (1985) The complete pattern of ocular dominance stripes in the striate cortex and visual field of the macaque monkey. J Neurosci 5:486-501.

Le Vay S, McConnell SK, Luskin MB (1987) Functional organization of primary visual cortex in the mink (Mustela vison), and a comparison with the cat. J Comp Neurol 257:422-441.

Linden DC, Guillery RW, Cucchiaro J (1981) The dorsal lateral geniculate nucleus of the normal ferret and its postnatal development. J Comp Neurol 203:189-211.

Linsker R (1986) From basic network principles to neural architecture: emergence of orientation columns. Proc Natl Acad Sci USA 83:87798783.

Livingstone MS, Hubel DH (1981) Effects of sleep and arousal on the processing of visual information in the cat. Nature 291:554-561.

Livingstone MS, Hubel DH (1984) Anatomy and physiology of a color system in the primate visual cortex. J Neurosci 4:309-356.

Löwel S, Singer W (1987) The pattern of ocular dominance columns in flat-mounts of the cat visual cortex. Exp Brain Res 68:661-666.

Löwel S, Freeman B, Singer W (1987) Topographic organization of the orientation column system in large flat-mounts of the cat visual cortex: a 2-deoxyglucose study. J Comp Neurol 255:401-415.

McConnell SK, Le Vay S (1986) Anatomical organization of the visual system of the mink, Mustela vison. J Comp Neurol 250:109-132.

Moody KD, Bowman TA, Lang CM (1985) Laboratory management of the ferret for biomedical research. Lab Anim Sci 35:272-279. 
Nakanishi H, Agranoff B, Kennedy C, Smith CB, Sokoloff L (1988) Use of $6{ }^{3} \mathrm{H}$-deoxyglucose in the measurement of local cerebral metabolic rate for glucose. Soc Neurosci Abstr 14:47.

Nudo RJ, Masterton RB (1986) Stimulus-induced ${ }^{14} \mathrm{C}$-2-deoxyglucose labeling of synaptic activity in the central auditory system. J Comp Neurol 245:553-565.

Olds JL, Frey KA, Ehrenkaufer RL, Agranoff BW (1985) A scquential double-label autoradiographic method that quantifies altered rates of regional glucose metabolism. Brain Res 361:217-224.

Redies C (1988) A quantitative double-label deoxyglucose method applied to sensory cortex. PhD Thesis, McGill University.

Redies C (1989) Double (Software package NS-020-S88). Neuroscience 30(2):I (Software Survey Section).

Redies C, Diksic M (1989a) The deoxyglucose method in the ferret brain. I. Methodological considerations. J Cereb Blood Flow Metabol $9: 35-42$.

Redies C, Diksic M (1989b) Tracer kinetic constants and simplified versions of the double-label deoxyglucose method. Neurosci 30:558561.

Redies C, Gjedde A (1989) Double-label and conventional deoxyglucose methods: a practical guide for the user. Cerebrovasc Brain Mctabol Rev 1:319-367.

Redies C, Diksic M, Evans AC, Gjedde A, Yamamoto YL (1987) Double-label autoradiographic deoxyglucose method for sequential measurement of regional cerebral glucose utilization. Neurosci 22: 601-619.

Redies C, Diksic M, Yamamoto YL (1989) The deoxyglucose method in the ferret brain. II. Glucose utilization images and normal values. J Cereb Blood Flow Metabol 9:43-52, 247-248.

Rockland KS (1985) Anatomical organization of primary visual cortex (area 17) in the ferret. J Comp Neurol 241:225-236.

Schoppmann A, Stryker MP (1981) Physiological evidence that the 2-deoxyglucose method reveals orientation columns in cat visual cortex. Nature 293:574-576.

Sharp FR, Kauer JS, Shepherd GM (1975) Local sites of activityrelated glucose metabolism in rat olfactory bulb during olfactory stimulation. Brain Res 98:596-600.

Singer W (1981) Topographic organization of orientation columns in the cat visual cortex. Exp Brain Res 44:431-436.
Sokoloff L, Reivich M, Kennedy C, DesRosiers MH, Patlak CS, Pettigrew KD, Sakurada O, Shinohara M (1977) The $\left[{ }^{14} \mathrm{C}\right]$ deoxyglucose method for the measurement of local cerebral glucose utilization: theory, procedure, and normal values in the conscious and anesthetized albino rat. J Neurochem 28:897-916.

Specht S, Grafstein B (1973) Accumulation of radioactive protein in mouse cerebral cortex after injection of ${ }^{3} \mathrm{H}$-fucose into the eye. Exp Neurol 41:705-722.

Stryker MP, Zahs KR (1983) ON and OFF sublaminae in the lateral geniculate nucleus of the ferret. J Neurosci 3:1943-1951.

Swindale NV (1980) A model for the formation of ocular dominance stripes. Proc R Soc Lond [Biol] 208:243-264.

Swindale NV (1982) A model for the formation of orientation columns. Proc R Soc Lond [Biol] 215:211-230.

Swindale NV, Matsubara JA, Cynader MS (1987) Surface organization of orientation and direction selectivity in cat area 18 . J Neurosci 7 : 1414-1427.

Tootell RBH, Hamilton SL, Switkes E (1988) Functional anatomy of macaque striate cortex. IV. Contrast and magno-parvo streams. J Neurosci 8:1594-1609.

van Essen D, Orbach HS (1986) Neuroscience: optical mapping of activity in primate visual cortex. Nature 321:564-565.

von der Malsburg C (1973) Self-organization of orientation sensitive cells in the striate cortex. Kybernetik 14:85-100.

von der Malsburg C, Cowan JD (1982) Outline of a theory for the ontogenesis of iso-orientation domains in visual cortex. Biol Cybern 45:49-56

Webster WR, Serviere J, Batini C, Laplante S (1978) Autoradiographic demonstration with $\left[{ }^{14} \mathrm{C}\right] 2$-deoxyglucose of frequency selectivity in the auditory system of cats under conditions of functional activity. Neurosci Lett 10:43-48.

Webster WR, Serviere J, Martin R, Hartley E (1983) Tonotopic bands produced by tones commenced long after 2-deoxyglucose injection. Neurosci Lett 40:281-286.

Wiesel TN, Hubel DH, Lam DMK (1974) Autoradiographic demonstration of ocular-dominance columns in the monkey striate cortex by means of transneuronal transport. Brain Res 79:273-279.

Young DA (1984) A local activator-inhibitor model for vertebrate skin patterns. Math Biosci 72:51-58. 